\title{
Alternatif Pembangkit Energi Listrik Menggunakan Prinsip Termoelektrik Generator
}

\author{
Sandy Anggriawan Sasmita ${ }^{1}$, Muhammad Taufiq Ramadhan ${ }^{1}$, Mochamad Iqbal Kamal ${ }^{1}$, Yohannes Dewanto ${ }^{1}$
}

\begin{abstract}
Thermoelectric generator (TEG) has been used to produce electrical energy, the working principle of TEG, the temperature difference between two materials, will flow current, and produce a potential difference. This principle is known as the "Seebeck effect" which is a reverse phenomenon of the Peltier (Thermoelectric Cooling, TEC) effect. This research was conducted to determine the electrical nergy capacity produced for 10 TEG modules in series. Testing is done by utilizing heat energy from asphalt, water flow and connected to 10 TEG modules. The test results show that the maximum voltage is 18Voltdc 0.49 Ampere.
\end{abstract}

KEYWORDS: Thermoelectric Generator, Peltier effect, Seebeck effect.

ABSTRAK: Pembangkit listrik termoelektrik (Thermoelectric Generator, TEG) telah digunakan untuk menghasilkan energi listrik, prinsip kerja TEG, perbedaan temperatur antar dua material, akan mengalirkan arus, dan menghasilkan beda potensial. Prinsip ini dikenal dengan "efek Seebeck" yang merupakan fenomena kebalikan dari efek Peltier (Thermoelectric Cooling, TEC). Penelitian ini dilakukan untuk mengetahui kapasitas energi listrik yang dihasilkanuntuk 10 modul TEG secara seri. Pengujian dilakukan dengan memanfaatkan energi panas dari aspal, aliran air dan terhubung pada 10 modul TEG. Hasil pengujian menunjukkan bahwa tegangan maksimal 18 Voltdc 0,49Ampere.

KATA KUNCI: Thermoelectric Generator, Peltier effect, Seebeck effect.

\section{PENDAHULUAN}

$\mathrm{T}$ ahun mendatang diperkirakan kebutuhan energi listrik akan semakin bertambah, seiring bertambahnya populasi manusia. Jika hanya mengandalkan sumber energi yang ada sekarang seperti batu bara, minyak dan gas yang sudah hampir habis, maka hal tersebut lama-kelamaan tidak bisa memenuhi kebutuhan akan energy, untuk aktivitas sehari-hari yang semakin banyak. Pantai Pandansimo yang terletak di desa Poncosari, Srandakan, Kabupaten Bantul, Provinsi Yogyakarta adalah salah satu tempat yang sudah menggunakan pembangkit listrik tenaga hibrida seperti pembangkit listrik tenaga angin dan solar sel, saat ini pembangkit tersebut dapat menghasilkan daya sebesar 90KW yang digunakan untuk menghidupkan kurang lebih 100 warung yang ada di sekitar pantai [3] . Tempat wisata pantai Pandansimo semakin lama semakin banyak pengunjung, maka dapat dipastikan penggunakan listrik akan semakin bertambah, oleh karena itu alternatif pembangkit listrik Termoelektrik Generator ini dapat digunakan untuk memenuhi kurangnya pasokan listrik.

\section{PENJABARAN IDE}

Teknologi Termoelektrik Generator merupakan sumber alternatif dalam memenuhi kebutuhan energi listrik. Termoelektrik generator adalah alat yang mengubah energi panas menjadi energi listrik. Di samping relatif ramah lingkungan, teknologi ini sangat efisien dan mampu menghasilkan energi dalam skala besar maupun kecil. Termoelektrik generator dapat di implementasikan pada rumah-rumah dipedesaan, yang belum terpasok listrik khususnya pada daerah yang beriklim tropis.

Oleh karena itu sangat cocok digunakan dipantai Pandansimo yang suhu rata ratanya adalah $35^{\circ} \mathrm{C}$.

\section{Rumusan Masalah}

Agar tujuan penelitian bisa dicapai dengan baik, masalah yang ada dirumuskan sebagai berikut:

a. Bagaimana cara menguji karakteristik dari termoelektrik generator.

b. Bagaimana cara mengukur tegangan listrik dari termoelektrik generator.

c. Bagaimana cara mengukur temperatur media uji (prototipe) menggunakan termometer infrared.

\section{Tujuan Penelitian}

Adapun tujuan yang ingin di capai pada penelitian, ini adalah:

a. Memperoleh kurva karakteristik Termoelektrik Generator.

b. Memperoleh data kenaikan tegangan dan kenaikan arus terhadap kenaikan suhu.

\section{Batasan Masalah}

Permasalahan yang dibahas pada tulisan ini, dibatasi sebagai berikut:

a. Pengujian dilakukan dengan mencatat perbedaan temperature (suhu), media uji (aspal), pada sisi hot side sebanyak 6 (enam) kali.

b. Bagian cold side dialirkan air, untuk menghilangkan panas, agar terjadi perbedaan suhu.

\footnotetext{
${ }^{1}$ Fakultas Teknologi Industri Jurusan Teknik Elektro Universitas Dirgantara Marsekal Suryadarma
} 
PENJABARAN TEKNIS

\section{Karakteristik Aspal sebagai kolektor Matahari}

Aspal adalah bahan hidrokarbon yang bersifat melekat (adhesive), berwarna hitam kecoklatan dan tahan terhadap air $^{[2]}$. Aspal tergolong dalam benda hitam ideal, Oleh karena kemampuan penyerapan radiasi yang tinggi menyebabkan aspal memiliki suhu yang tinggi pada saat siang hari.

Melihat potensi dalam penyerapan radiasi matahari yang efektif maka panas aspal sangat cocok dimanfaatkan sebagai kolektor energi matahari, yang selanjutnya dapat dikonversi menjadi bentuk energi listrik.

\section{Dasar Ilmu TEG}

Perbedaan suhu pada dua komponen Bismuth dan Telluride, menyebabkan perpindahan elektron dari kutub negatif ke kutub positif, semakin besar perbedaan suhu, maka semakin cepat perpindahan elektron, sehingga arus yang dihasilkan, akan semakin besar [1].

\section{Karakteristik TEG}

Prinsip kerja dari TEG adalah berdasarkan efek Seebeck yaitu "jika 2 (dua) buah material semikonduktor yang berbeda disambungkan pada salah satu ujungnya, kemudian diberikan suhu yang berbeda pada sambungan, maka terjadi perbedaan tegangan pada ujung yang satu dengan ujung yang ujung yang lain" [1]. Umumnya bahan semikonduktor yang digunakan pada susunan TEG adalah Bismuth dan Telluride.

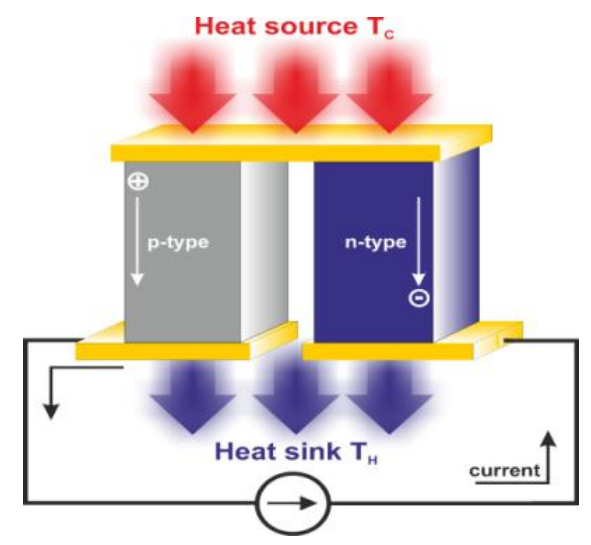

- Gambar 1. Struktur TEG

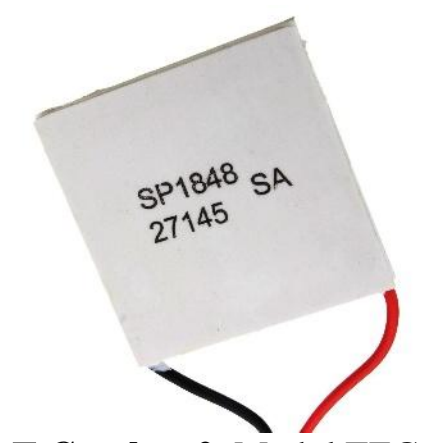

- Gambar 2. Modul TEG

Struktur TEG dapat dilihat pada Gambar 1. tersebut menunjukkan struktur TEG yang terdiri dari susunan elemen tipe-N (material kekurangan electron) dan tipe-P (material kelebihan electron). Panas masuk pada salah satu sisi TEG dan panas tersebut dibuang melalui sisi lainnya. Proses transfer panas tersebut menghasilkan suatu tegangan yang melewati sambungan struktur TEG dan besarnya tegangan yang dihasilkan sebanding dengan perbedaan temperatur. Sedangkan Gambar 2, adalah modul TEG yang ada di pasaran.

\section{Metodologi}

Struktur rancangan termoelektrik generator pada penelitian ini dapat dilihat pada gambar 3 . 


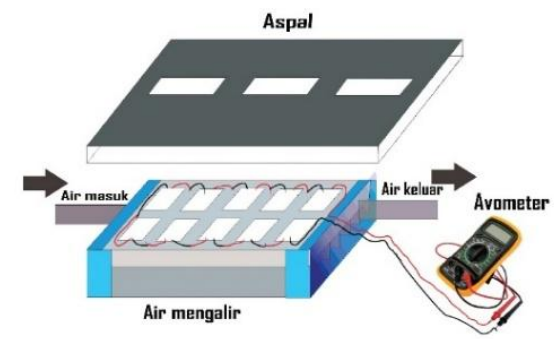

שambar 3. Rancangan Prototipe Alat Pengujian Aspal sebagai Kolektor Panas dan Aliran Air untuk Pembuangan Panas.

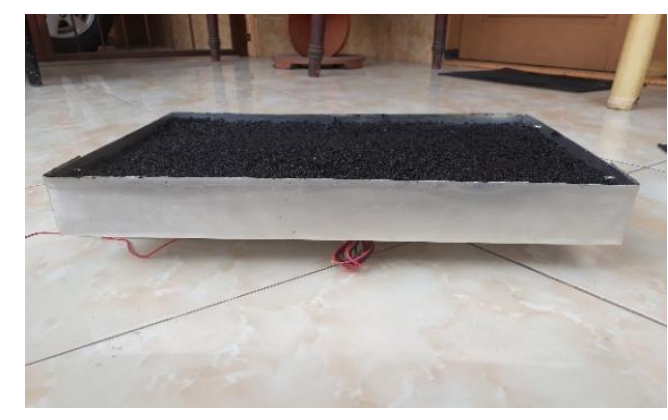

- Gambar 4. Prototype Alat yang Sudah Jadi.

Prototipe pada Gambar 4, dirancang menggunakan 10 modul TEG yang disusun secara seri. Komponen sistem ini diawali dengan lapisan aspal pada wadah alumunium, dibagian bawah terdapat waterblock sebagai tempat untuk aliran air yang berfungsi untuk melepas panas agar terjadi perubahan suhu $(\Delta T)$, antara aspal dan aliran air.

\section{Metode Pengambilan Data}

Pengambilan data, dilakukan pada siang hari pukul 13:00 sampai 14:00 WIB (60menit) hal ini, dikarenakan pada siang hari, intensitas matahari lebih banyak, sehingga aspal dapat menyerap panas dengan efektif. Pengambilan data, untuk penelitian ini adalah dengan mencatat kenaikan suhu aspal dan kenaikan tegangan pada keluaran alat uji selama 10 menit. Pengambilan data, menggunakan alat ukur termometer infrared, untuk mengukur suhu aspal, suhu aliran air. Sedangkan untuk mengukur tegangan yang dari alat pengujian digunakan Avometer digital.

\section{HASIL PENELITIAN}

Hasil penelitian yang dilakukan selama 60 menit dari pukul 13.00 sampai 14.00 adalah: Suhu air $=25^{\circ} \mathrm{C}$

Suhu awal aspal $=30^{\circ} \mathrm{C}$

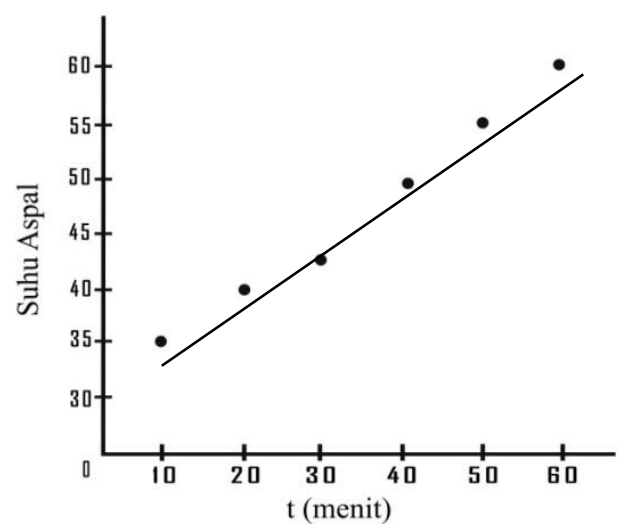

- Gambar 5. Grafik Peningkatan Suhu Aspal terhadap Waktu selama 60 Menit dari Pukul 13.00 sampai 14.00 WIB. 
- Tabel 1. Data Kenaikan Suhu Aspal Setiap 10 Menit

\begin{tabular}{cc}
\hline Menit ke- & Suhu Aspal \\
\hline 10 & $35^{\circ} \mathrm{C}$ \\
20 & $40^{\circ} \mathrm{C}$ \\
30 & $43^{\circ} \mathrm{C}$ \\
40 & $50^{\circ} \mathrm{C}$ \\
50 & $57^{\circ} \mathrm{C}$ \\
60 & $60^{\circ} \mathrm{C}$ \\
\hline
\end{tabular}

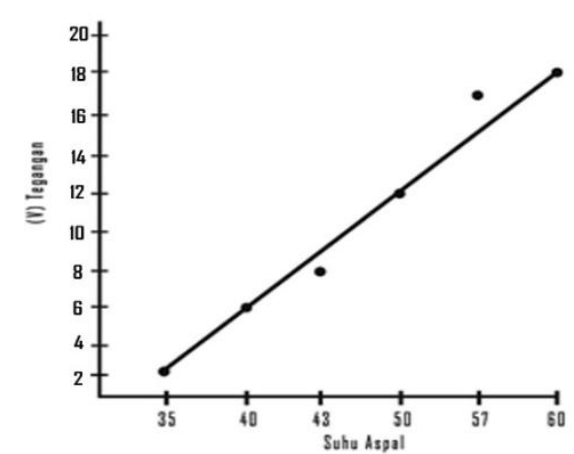

- Gambar 6. Grafik Peningkatan Tegangan Terhadap Suhu Aspal.

Dari kedua grafik tersebut maka di dapat hubungan kenaikan suhu aspal berbanding lurus dengan tegangan.

Tabel 2. Kenaikan Suhu Terhadap Perubahan Tegangan

\begin{tabular}{cc}
\hline Suhu Aspal & Tegangan (Volt) \\
\hline $35^{\circ} \mathrm{C}$ & 2 \\
$40^{\circ} \mathrm{C}$ & 6 \\
$43^{\circ} \mathrm{C}$ & 8 \\
$50^{\circ} \mathrm{C}$ & 12 \\
$57^{\circ} \mathrm{C}$ & 17 \\
$60^{\circ} \mathrm{C}$ & 18 \\
\hline
\end{tabular}

I(Arus) diapat dari hasil pengukuran menggunakan Avometer pada tegangan 2,6,8,12,17,18 Volt

- Tabel 3. Pengukuran Arus Yang Dihasilkan Dan Penghitungan Daya

\begin{tabular}{ccccc}
\hline Menit ke- & Suhu Aspal & Tegangan (Volt) & I (Amp) & Daya (Watt) \\
\hline 10 & $35^{\circ} \mathrm{C}$ & 2 & 0.08 & 0.16 \\
20 & $40^{\circ} \mathrm{C}$ & 6 & 0.18 & 1.08 \\
30 & $43^{\circ} \mathrm{C}$ & 8 & 0.22 & 1.76 \\
40 & $50^{\circ} \mathrm{C}$ & 12 & 0.33 & 3.96 \\
50 & $57^{\circ} \mathrm{C}$ & 17 & 0.42 & 7.14 \\
60 & $60^{\circ} \mathrm{C}$ & 18 & 0.49 & 8.82 \\
\hline
\end{tabular}

- Tabel 4. Estimasi Anggaran Pembuatan Prototype Alat

\begin{tabular}{cccc}
\hline Nama Komponen & Quantity & $\begin{array}{c}\text { Harga Satuan } \\
{[\mathbf{R p}]}\end{array}$ & $\begin{array}{c}\text { Total Harga } \\
{[\mathbf{R p}]}\end{array}$ \\
\hline Modul TEG & 10 & 100.000 & 1.000 .000 \\
Heatsink 40x12x3.5cm & 1 & 150.000 & 150.000
\end{tabular}


Sandy Anggriawan Sasmita, Muhammad Taufiq Ramadhan, Mochamad Iqbal Kamal, dan Yohannes Dewanto

Heatsink 26x12x3.5cm

Aspal

Plat aluminium 50x50cm

Thermalpasta

Selang air
1

100.000

100.000

$5 \mathrm{~kg}$

100.000

100.000

1

50.000

50.000

2

40.000

80.000

$10 \mathrm{~m}$

6.000

60.000

\section{KESIMPULAN}

Berdasarkan hasil pengujian, dapat disimpulkan sebagai berikut:

1. Pengaruh panas matahari yang ada, mengakibatkan Generator Termoelektrik yang tersusun seri sebanyak 10 buah modul TEG, dengan $\Delta \mathrm{T} 35^{\circ} \mathrm{C}$, mampu menghasilkan tegangan $18 \mathrm{Vdc}$ dan arus listrik sebesar $0,49 \mathrm{~A}$.

2. Secara garis besar, daya yang dihasilkan dari Generator Termoelektrik ini masih cukup kecil. Akan tetapi, penelitian ini menunjukan bahwa pembangkit termoelektrik memiliki prospek yang cerah dimasa depan sebagai sumber energi alternatif.

3. Aplikasi Generator Termoelektrik cocok, digunakan untuk daerah beriklim tropis.

\section{UCAPAN TERIMA KASIH}

1. NEST UI 2018, Inovasi Pembangkit Listrik untuk Daerah 3T.

2. Prodi elektro, Fakultas Teknologi Industri, Universitas Dirgantara Marsekal Suryadarma.

\section{DAFTAR PUSTAKA}

[1] Culp, Archie, W., 1984, Principles of Energy Convertion. Diterjemahkan oleh Darwin Sitompul dan Khusnul Hadi dengan judul Prinsip-prinsip Konversi Energi. Jakarta, Erlangga.

[2] Diansari, Serpiskha, 2016, Aspal Modifikasi Dengan Penambahan Plastik Low Linear Density Poly Eethylene (LLDPE) Ditinjau DariKarakteristik Marshall Dan Uji Penetrasi Pada Lapisan Aspal Beton (AC-BC). Jurusan Teknik Sipil-Fakultas Teknik Universitas Lampung.

[3] Pradityo, J.,Winardi,B.,\& Nugroho,A.,2015, Evaluasi Dan Optimasi Sistem OFF GRID Pembangkit Listrik Tenaga Hybrid(PLTH) Bayu Baru,Bantul, D.I. Yogyakarta., Jurusan Teknik Elektro- Universitas Diponegoro Semarang 